\title{
Built environment inspired by nature: a case study of human skin
}

\author{
H. Ahmad \& H. Taleb \\ Sustainable Design of the Built Environment, \\ British University in Dubai, UAE
}

\begin{abstract}
The word 'biomimicry' appeared for the first time in scientific literature in 1962 and increased in usage - especially among materials scientists in the 1980s. Biomimicry "is learning from and then emulating natural forms, processes, and ecosystems to create more sustainable designs". Nowadays, biomimicry focuses on different areas such as working to build free policies that make use of it. This basically resolves challenges related to sustainability, supports educational programmes for professionals and students and encourages profitable organisations to use biomimicry and give economic support to biodiversity. Human skin is the natural concept utilised for this report. By analysing its characteristics and using ECOTECT software for analysis and stimulation, new strategies were applied inspired by human skin on an existing building to enhance sustainability and efficiency in areas such as the building envelope, filtration system, double glazing performance, vapour barrier system, evaporative cooling system and enhancing shading devices. The aim of this report is to mimic the natural function and analyse nature to innovate life-friendly and sustainable solutions within an existing architectural case study located in the United Arab Emirates - Sharjah Al-Rahmania, 4. The findings of this paper are that human skin as a natural concept can be a useful concept to learn from. After analysing adaptation of different strategies related to human skin, suitable solutions were tagged to create a good framework within the chosen case study.
\end{abstract}

Keywords: biomimicry, ECOTECT software, sustainable buildings, vapour barriers, evaporative cooling. 


\section{Introduction}

The word 'biomimicry' appeared for the first time in scientific literature in 1962, increasing in usage especially between materials scientists in the years of the 1980s [1]. What is biomimicry? "bio" = life and living things "mimicry" = copying and therefore biomimicry is a design tool based on emulating strategies used by living things [2]. In addition Baumeister, Tocke, Dwyer, Ritter, and Benyus claimed that biomimicry "is learning from and then emulating natural forms, processes, and ecosystems to create more sustainable designs". Nowadays biomimicry focuses on areas such a working to build free policies that make use of it to resolve challenges related to sustainability, support educational programmes for professionals and students and encouraging organisations to give economic support to biodiversity [3]. Knowledge of biomimicry offers designers a different framework. There are nine basic rules of the circle of life that should be highlighted here. Nature works on sunlight, creates a suitable shape to function, uses just the energy it requires, features equivalent collaboration, recycles everything, requires different local expertise, banks on variety and restrains extremes from within. The objective of this report is to mimic the nature function plus analyzing the nature to innovate life friendly and sustainability solutions within an existing architectural case study which is located in similar climatic condition.

\section{Conceptual framework}

\subsection{Natural concept}

Natural inspiration for this project comes from human skin.

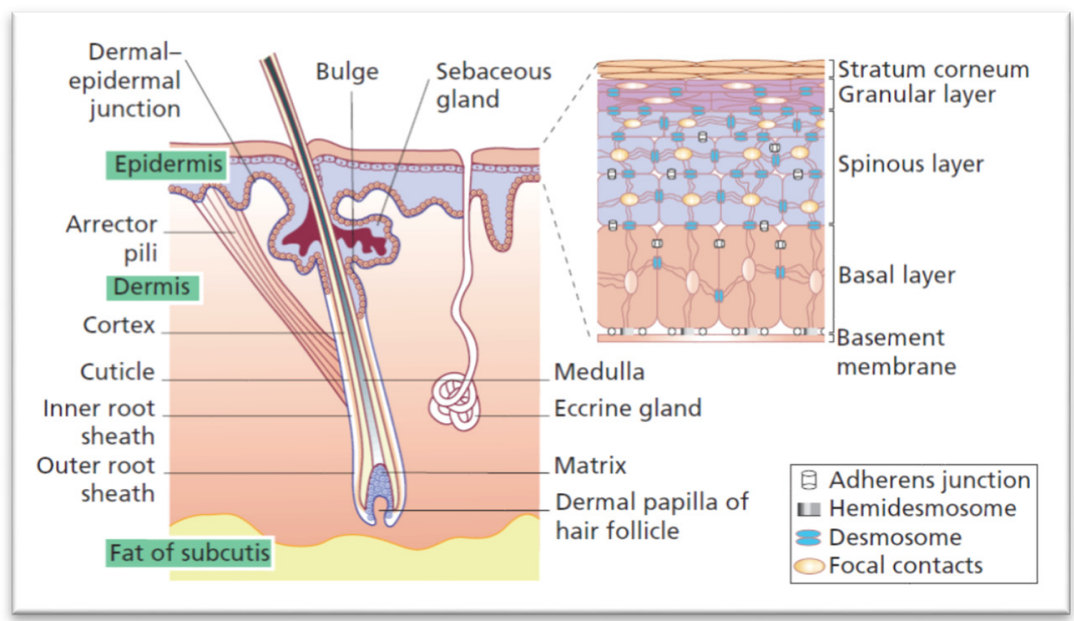

Figure 1: Natural concept. 


\subsection{Bio inspired strategies}

\subsubsection{Enhancing building envelope}

Human skin is the external covering tissue of the body; skin protects the organs and internal cells from the external environment. The skin is one of the biggest organs of the human body [4].

2.2.1.1 Extracted strategy A building envelope acts as a skin and includes every building element that separates the inside from the outside. Building envelopes consist of foundations, exterior walls, windows, doors and the roof [5]. All architects and designers focus on the building skin for one reason; it is continually active in protecting the interior population. The building envelope is also usually the first impression people get about the design of any project [6]. However, having a good design for the building envelope can help to determine the different quantities of cooling, lighting and heating any building will require [7].

\subsubsection{Filtration system}

Human skin protects the body from the impact of the microbes, chemicals and different microorganisms that entering the human body [8].

2.2.2.1 Extracted strategy Filters are machinery used to control and clean gases and liquids from suspended particles using filtration system [9]. Air filters are one of the essential parts of a heating, ventilation and air conditioning (HVAC) system. It is used to provide good quality indoor air and to control air humidity and temperature. The simplest air filter is a container divided via a filter membrane into two different parts, one of them dirty and the other clean. Differences in pressure between the gases and liquids control the flow of the fluid through the filter. Also, according to the United States Environmental Protection Agency (EPA) the vegetation and trees surrounding a building play a huge part in filtering the air for contaminants such as Co2, Vocs, So2, No2 and other air pollutants through their twigs ,leaves, and stems. In this case we can improve environmental indoor quality and indoor air quality inside a building in a way that will impact on the occupant's health, performance and comfort, as well as work to reduce temperatures in the interior by shading the building and blocking winds during the year.

\subsubsection{Double glazing performance}

Human skin is composed of three layers: the epidermis is the first and outer layer including the main protective structure, the dermis is a second fibrous layer that supports the epidermis and third is the subcutis, a subcutaneous layer. The skin controls human body temperature and allows feelings of cold, heat and touch [10].

2.2.3.1 Extracted Strategy The double-glazed windows consist of two glass layers with a small gap of around $16 \mathrm{~mm}$ between them filled with a layer of air or gas [11]. The aim is to provide an insulating barrier against outside temperatures. 
The properties for the glass used is a coated surface to prevent warm temperatures entering in a hot climate like the UAE and re-radiating high temperatures in a cold climate [12].

\subsubsection{Vapour barrier system}

The epidermis is the outer layer of the human skin, the main property of the epidermis is that provides a waterproof barrier and controls the humidity of the skin [13].

2.2.4.1 Extracted strategy A vapour barrier system is used to control air and moisture movements, this system does not working as a barrier, but as a Vapour Diffusion Retarder (VDR). The VDR controls moisture movement from outside in or from inside out at the level of the molecules [14]. However, the most important objective of this system is preventing the passage of water vapour that exists in the air and controlling humidification inside the building. Polyethylene plastic film is one of the most common vapour barrier materials, with the thickness of this material being around $(0.05 \mathrm{~mm}$ to $0.2 \mathrm{~mm})$ [15].

\subsection{Strategy implementation}

Architects and designers focus on the building envelope because it is the key to being more sustainable, reducing heat gains and heat loss and the impact of the load on the HVAC system, especially in the UAE. A further improvement to the building envelope comes by updating the existing wall materials. More improvements to the existing building can be made by replacing the existing single-glazed window with an aluminium frame with a high U-value, doubleglazed as shown in Figure 2. As the building is located in a hot climate, we need to apply the vapour barrier system from the exterior side of building to control the amount of moisture that comes from outside the building, as shown in Figure 3.

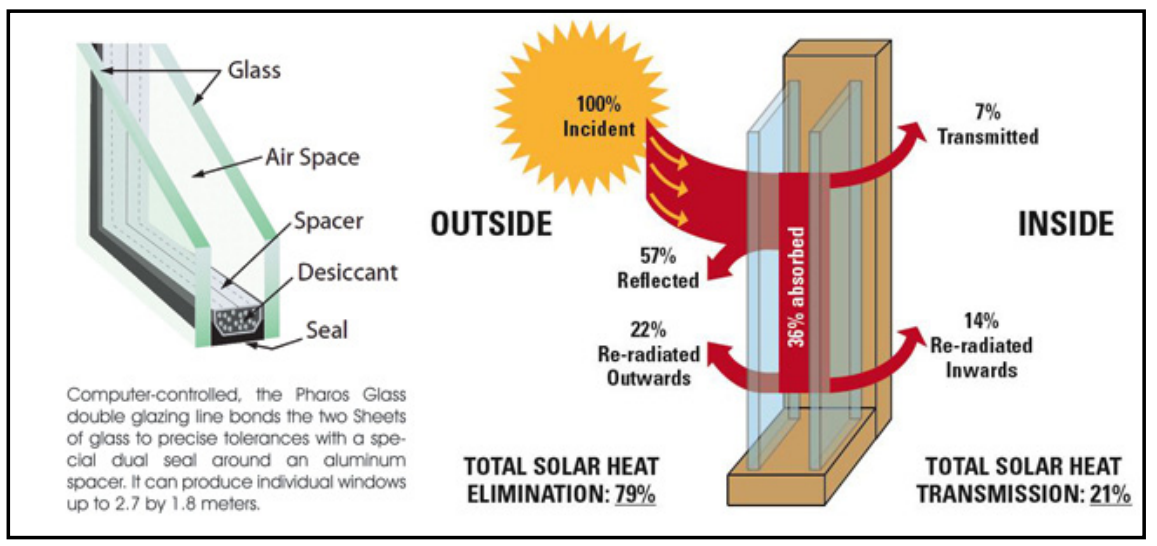

Figure 2: Double-glazing. 


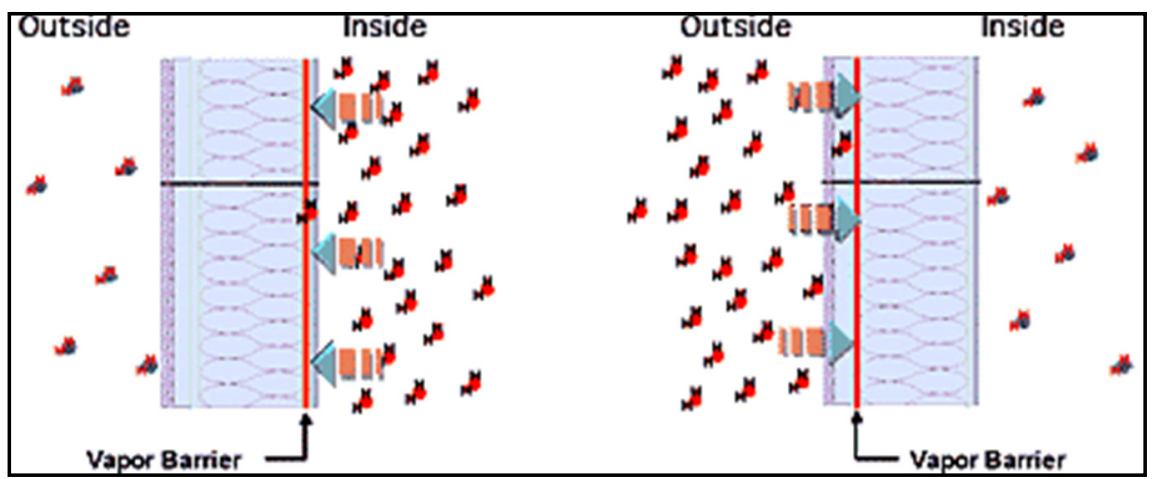

Figure 3: Typical vapour barrier location in the wall assembly.

\section{Methodology}

This project follows these steps by choosing a natural concept (human skin) and then mimicking the natural functions and analysing nature to innovate life-friendly and sustainable solutions within an existing architectural case study is located in similar climatic conditions.

Building performance with the new strategies is evaluated with simulation software IES VE (Integrated Energy Simulation) and the outcomes are compared to the original case.

\section{Case study}

The study takes place in Sharjah, in the United Arab Emirates. The villa is located in Sharjah-Al-Rahmania, 4.

The total area for the villa is $345.12 \mathrm{~m}^{2}$ and the volume is $1,215 \mathrm{~m}^{3}$. The villa consists of 1 guest bedroom, 1 majlis, 1 dining room, 1 family lounge, 4 bathrooms and a kitchen on the ground floor plan. The first floor consists of 1 master bedroom, 4 bedrooms, 5 bathrooms and a family lounge. With reference to weather data simulation generated from the climate consultant software; it has been found that Sharjah has extremely high temperatures and very humid areas as shown in Figure 4.

The temperature range chart shows the difference between temperatures across the year, it ranges between 5 and 44 cilices and reaches the maximum in July and August months.

\subsection{Simulation models}

By using ECOTECT software for analysis and simulation, new strategies that inspired from a human skin were applied to the existing building to enhance the sustainability and efficiency of the building. 


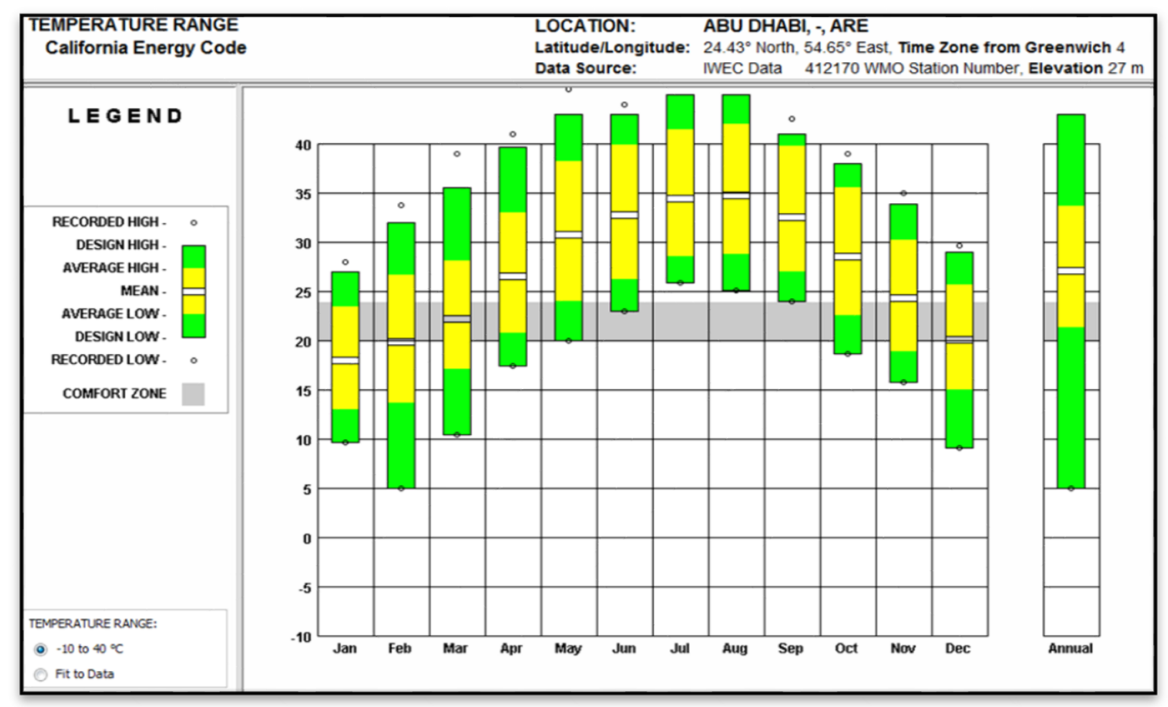

Figure 4: Temperature range in Sharjah region.
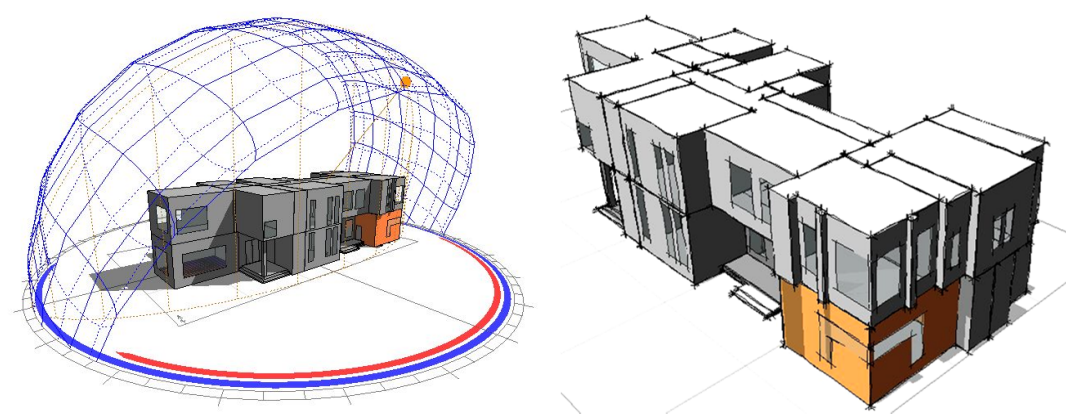

Figure 5: Model of the building by ECOTECT.

\section{Data and analysis}

Table 1 shows the monthly heating/cooling load. Before applying the doubleglazed window the amount of cooling load was around 35,488,444 MWh/year. After applying the double-glazed windows - Low E - with a timber frame, the cooling load will reduce and the building will be more comfortable and efficient. Analysing the monthly heating and cooling load after improving the building envelope with double glazing shows that energy consumption used for the cooling load reduced to around (40\%) or 16,710,706 MWh/year (Table 2) (Figure 6). 
Table 1: Monthly heating/cooling (before) improving. Ecotect: 2014.

\begin{tabular}{cccc}
\hline & HEATING & COOLING & TOTAL \\
\hline MONTH & $(\mathrm{Btu})$ & $(\mathrm{Btu})$ & $(\mathrm{Btu})$ \\
\hline-------- & ---- & ---- \\
Jan & 11135 & 118597 & 129733 \\
Feb & 2554 & 792959 & 795513 \\
Mar & 0 & 1128002 & 1128002 \\
Apr & 0 & 2405513 & 2405513 \\
May & 0 & 3763848 & 3763848 \\
Jun & 0 & 4288340 & 4288340 \\
Jul & 0 & 5098692 & 5098692 \\
Aug & 0 & 5382600 & 5382600 \\
Sep & 0 & 4902784 & 4902784 \\
Oct & 0 & 4170230 & 4170230 \\
Nov & 0 & 2777984 & 2777984 \\
Dec & 0 & 645205 & 645205 \\
--------- & ------- & ------- & ------- \\
TOTAL & 13690 & 35474756 & $\underline{35488444}$ \\
--------- & ------- & ------- & ---- \\
PER M & 411 & 1065948 & 1066360 \\
Floor & $358.22 \mathrm{ft}^{2}$ & & \\
Area: & & & \\
\hline
\end{tabular}

Table 2: Monthly heating/cooling (after) improving. Ecotect: 2014.

\begin{tabular}{|c|c|c|c|}
\hline & HEATING & COOLING & TOTAL \\
\hline MONTH & (Btu) & (Btu) & (Btu) \\
\hline ------------- & --------- & ---------- & ---------- \\
\hline Jan & 0 & 55199 & 55199 \\
\hline Feb & 0 & 415343 & 415343 \\
\hline Mar & 0 & 731071 & 731071 \\
\hline Apr & 0 & 1776222 & 1776222 \\
\hline May & 0 & 3093798 & 3093798 \\
\hline Jun & 0 & 3555746 & 3555746 \\
\hline Jul & 0 & 4227288 & 4227288 \\
\hline Aug & 0 & 4385916 & 4385916 \\
\hline Sep & 0 & 3715728 & 3715728 \\
\hline Oct & 0 & 2818686 & 2818686 \\
\hline Nov & 0 & 1593320 & 1593320 \\
\hline Dec & 0 & 342389 & 342389 \\
\hline TOTAL & 0 & 26710706 & 16710706 \\
\hline ------------ & ------ & ---------- & -------- \\
\hline PER $\mathrm{M}^{2}$ & 0 & 802605 & 802605 \\
\hline $\begin{array}{c}\text { Floor } \\
\text { Area } \\
\end{array}$ & $358.22 \mathrm{ft}^{2}$ & & \\
\hline
\end{tabular}




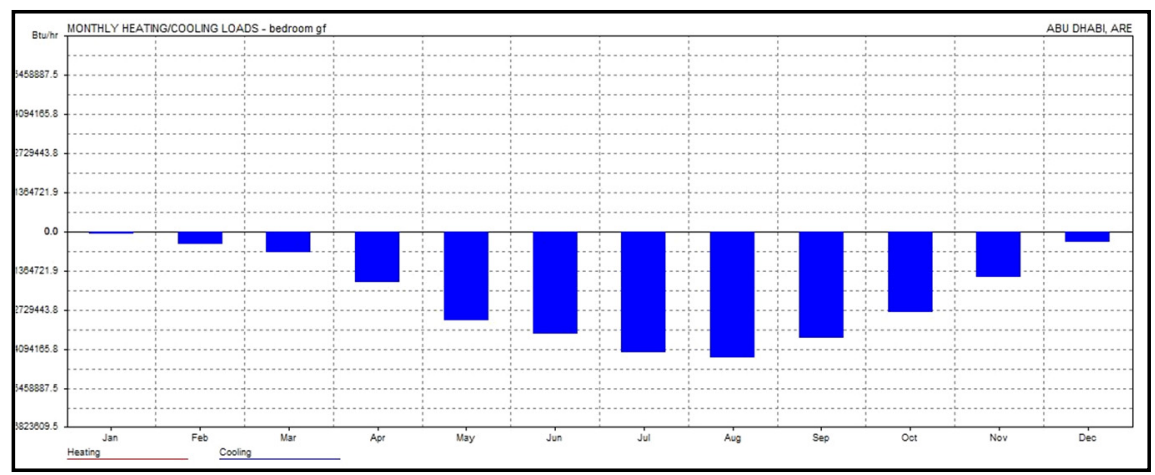

Figure 6: Monthly heating/cooling after improving the double-glazed window. Ecotect: 2014.

By analysing the hourly gains in July, heat gain that enters the existing building will reduce and the building will become more sustainable and more thermally comfortable for occupants by reducing the heat gains. The total loads on the HVAC system in that month were around $15,947.13 \mathrm{MWh} /$ year, a reduction of around $9 \%$ as shown in Figure 7.

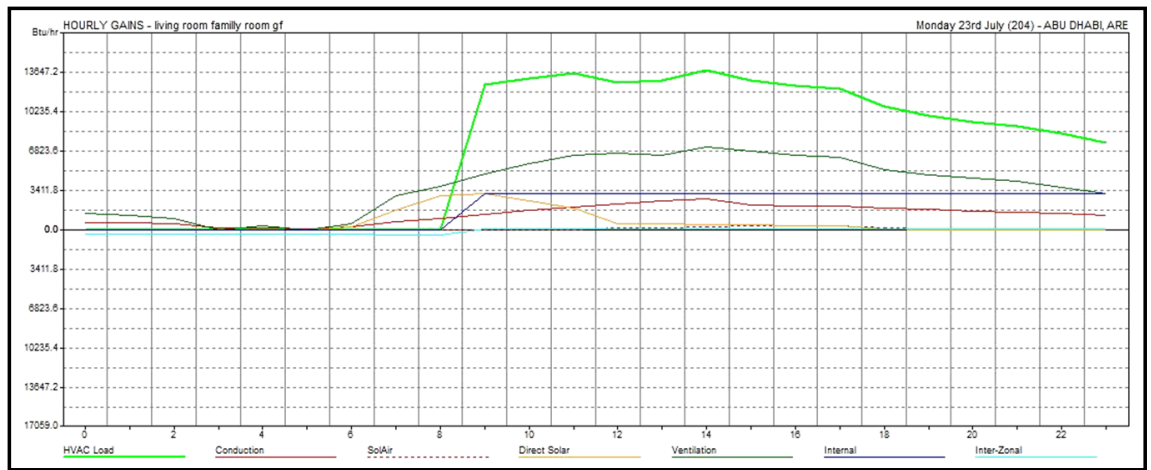

Figure 7: Hourly gains in July after improving the building envelope. Ecotect: 2014.

Analysing the monthly heating and cooling load level in the building envelope after modification by adding a brick cavity concrete block plaster with U-value $0.30292 \mathrm{~W} / \mathrm{m} 2 \mathrm{k}$ and different isolation layers the load of HVAC system will show a reduction in the consumption of electricity. The cooling load reached around 27,263 MWh/year, as shown in Figure 8. 


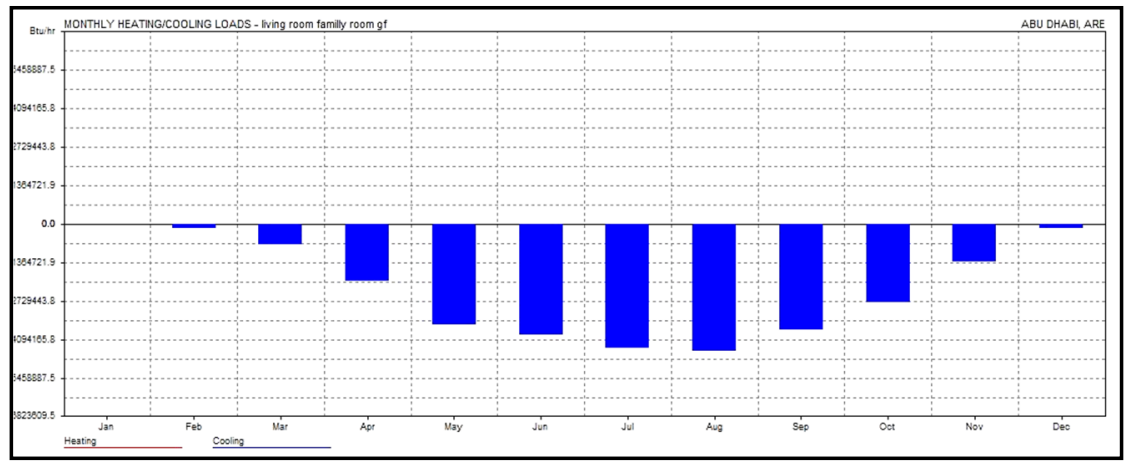

Figure 8: Monthly heating/cooling load after improving the wall insulation. Ecotect: 2014.

\section{Conclusion}

The aim of this report is to mimic a natural function and analyse the nature to innovate life-friendly and sustainable solutions within an existing architectural case study located in a similar climatic condition. Human skin as a natural concept can be a useful concept to learn from. After analysing the adaptation of different strategies of the human skin, highlighting suitable solutions and creating a good framework for a case study - a villa - it was possible to find suitable solutions to work out problems which were discovered throughout the assessment of existing building design. By using ECOTECT software for analysis and simulation, these new strategies inspired by human skin were tested on the existing building to enhance sustainability and efficiency.

\section{References}

[1] Pawlyn, M., biomimicry in architecture. RIBA Enterprises, pp. 136, 2011.

[2] The Biomimicry Institute, Biomimicry Innovation Inspired by Nature. Paper presented at IBE Annual Conference, 6-9 March. 2008.

[3] Graphic design + biomimicry, http://scholarworks.rit.edu/theses/7019/.

[4] Innerbody,www.innerbody.com/image_nervov/nerv17-new4.html.

[5] Homeowner Protection Office, Building Envelope Guide for Houses: Residential construction, Part 9. British Columbia, www.hpo.bc.ca/ building-envelope-guide-houses.

[6] Yowell, J. Biomimetic Building Skin: A Phenomenological Approach Using Tree Bark As Model. pp. 1-71. 2011.

[7] Center For Climate And Energy Solutions. Building Envelope | Center for Climate and Energy Solutions. www.c2es.org/technology/factsheet/ BuildingEnvelope.

[8] Taghizadeh, K. and Bastanfard, M. The Anatomy of a Human Body, a Model to Design Smart High Building. Science and Technology, 2(1) pp. 8-14. 2012. 
[9] Filters.www.thermopedia.com/content/762/.

[10] Encyclopedia Britannica, human skin (anatomy), The dermis. www.global. britannica.com/EBchecked/topic/547591/human-skin/26789/The-dermis.

[11] Energy Saving Trust, The Energy Saving Trust's guide to energy efficient windows. www.energysavingtrust.org.uk/Insulation/Windows.

[12] WiseGEEK. www.wisegeek.com/what-are-double-glazed-windows.htm.

[13] Webmd.boots.com. The skin (human anatomy): Picture, definition, function and skin conditions. www.webmd.boots.com/skin-problems-andtreatments/guide/picture.

[14] Ecohome, www.ecobuildingpulse.com/building-science/understandingvapor-barriers.aspx.

[15] Wulfinghoff, D. Energy efficiency manual. Wheaton, Md.: Energy Institute Press. 1999. 